\title{
Effect of Bolus Volume and Consistency on Swallowing Events Duration in Healthy Subjects
}

\author{
Weslania V Nascimento, Rachel A Cassiani, Carla M Santos, and Roberto 0 Dantas* \\ Division of Gastroenterology of the Department of Medicine, Medical School of Ribeirão Preto, University of São Paulo, Ribeirão Preto SP, Brazil
}

\begin{abstract}
Background/Aims
Swallowing is a complex function with the control of the swallowing center being located in the brain stem. Our aim in this investigation was to evaluate, in healthy volunteers, the oral and pharyngeal transit of 2 bolus volumes and 2 consistencies, and the influence of these boluses on the proportion of pharyngeal clearance duration/hyoid movement duration.

\section{Methods}

Videofluoroscopic evaluation of swallows was performed in 30 healthy volunteers, aged 29-77 years (mean 58 years). The subjects swallowed in duplicate of $5 \mathrm{~mL}$ and $10 \mathrm{~mL}$ of thick liquid barium and honey thick barium. We measured the duration of oral transit, pharyngeal transit, pharyngeal clearance, upper esophageal sphincter opening, hyoid movement, oropharyngeal transit, and the relation pharyngeal clearance duration/hyoid movement duration.
\end{abstract}

\section{Results}

A $10 \mathrm{~mL}$ bolus volume caused a longer UES opening duration than a $5 \mathrm{~mL}$ bolus volume, for both consistencies. The pharyngeal transit was longer for honey thick bolus consistency than for thick liquid, with both the volumes of $5 \mathrm{~mL}$ and $10 \mathrm{~mL}$. For pharyngeal clearance, the difference was significant only with the $10 \mathrm{~mL}$ bolus volume. There was no difference associated with bolus volume or consistency in the relation between pharyngeal clearance duration and hyoid movement duration.

\section{Conclusions}

Increase in the swallowed bolus volume causes a longer UES opening duration and an increase in bolus consistency from thick liquid to honey thick causes a longer pharyngeal transit duration. The proportion between pharyngeal clearance and hyoid movement does not change with bolus volume or bolus consistency.

\section{(J Neurogastroenterol Motil 2015;21:78-82)}

\section{Key Words}

Deglutition; Esophageal sphincter, upper; Pharynx

Received: April 26, 2014 Revised: July 8, 2014 Accepted: August 4, 2014

(c) This is an Open Access article distributed under the terms of the Creative Commons Attribution Non-Commercial License (http://creativecommons. org/licenses/by-nc/3.0) which permits unrestricted non-commercial use, distribution, and reproduction in any medium, provided the original work is properly cited.

*Correspondence: Roberto O Dantas, MD

Departamento de Clínica Médica, Faculdade de Medicina de Ribeirão Preto, Av. Bandeirantes 3900, 14049-900 Ribeirão Preto, São Paulo, Brazil

Financial support: None.

Tel: +55-16-36022457, Fax: +55-16-36020229, E-mail: rodantas@fmrp.usp.br

Conflicts of interest: None.

Author contributions: Weslania V Nascimento works in data acquisition, data analysis, and in the writing of the manuscript; Rachel A Cassiani and Carla M Santos works in data acquisition and analysis; and Roberto $O$ Dantas participated in the data acquisition, analysis, and in the writing the manuscirpt. All Althors approved the final form of the manuscript. 


\section{Introduction}

Swallowing is a complex function with the control of the swallowing center being located in the brain stem. This control receives information from mouth, pharyngeal and proximal esophagus to make the adaptations to the characteristics of the swallowed bolus, in terms of volume, consistency, temperature and taste. ${ }^{1-3}$

The adaptation to bolus volume and consistency is important, because the loss of this control may cause dysphagia and air way aspiration, with impairment of hydration, nutrition, impact on quality of life, increased risk of pulmonary infectious disease and death.

The bolus viscosity utilized in investigations and in the treatment of dysphagic patients has a large range. ${ }^{4}$ Previous differences found among publications about the evaluation of swallowing may be the consequences of this large variation of the viscosity of the swallowed bolus utilized in each investigation. ${ }^{5}$ The importance of the knowledge of the effect of bolus viscosity and volume on swallowing is that for the treatment in which we must indicate the correct consistency and swallowing bolus volume for a particular patient with dysphagia. Modifications of food texture and liquid thickness have an important role on dysphagia treatment. $^{6}$

Upper esophageal sphincter (UES) opening and closing are associated with the hyoid movement. ${ }^{7}$ Pharyngeal transit is related to UES opening and the offset of UES opening should occur after the completion of the pharyngeal clearance. If the sphincter closes before the completion of pharyngeal clearance, bolus residues may be present on pharynx and aspiration may occur. It is important that there is a correct proportion between pharyngeal clearance duration and hyoid movement duration, which could be influenced by bolus volume and/or consistency.

Our aim in this investigation was to evaluate the oral and pharyngeal transit duration of 2 bolus volumes $(5 \mathrm{~mL}$ and 10 $\mathrm{mL}$ ) of thick liquid and honey thick consistencies in healthy volunteers, and the influence of these bolus volumes and consistencies on the proportion of pharyngeal clearance duration/hyoid movement duration. The hypothesis was that the modification of bolus volume and consistency to cause alteration in bolus transit duration but the proportion of pharyngeal clearance duration/hyoid movement duration was preserved.

\section{Materials and Methods}

Videofluoroscopic evaluation of swallows was performed in 30 healthy volunteers, 18 men and 12 women, aged 29-77 years and mean of 58 years. None of the volunteers had dysphagia, gastroesophageal reflux symptoms, previous surgery of the head, neck, esophagus, or stomach, respiratory and neurologic diseases, or problem with the ingestion of any kind of food. The investigation was approved by the Human Research Committee of the University Hospital of Ribeirão Preto USP. Written informed consent was given by all volunteers.

Used for videofluoroscopy was the Arcomax Phillips model BV 300 (Veenpluis, The Netherlands) radiologic instrument and the Ever Focus model EDSR 100 V1.2 (Taipei, Taiwan) digital image processing system with a DVR (Ever Focus) monitor, run at 60 frames/sec, with a clock time that indicates digital time in seconds and number of frames on each video frame.

Each subject was studied while sitting in a chair, turned laterally to the image intensifier. Lateral images were obtained of the mouth, pharynx and proximal esophagus. The subjects swallowed in duplicate of $5 \mathrm{~mL}$ and $10 \mathrm{~mL}$ of thick liquid barium (100\% barium sulfate, Bariogel, Laboratório Cristália, Itapira, SP, Brazil) and $5 \mathrm{~mL}$ and $10 \mathrm{~mL}$ of honey thick barium, prepared with 50 $\mathrm{mL}$ of thick liquid barium plus $4.5 \mathrm{~g}$ of instant food thickener (Thick \& Easy, Hormel Health Labs, Savannah GA, USA).

The following features were timed: (1) onset of propulsive tongue tip movement at the maxillary incisors, (2) onset and end of the hyoid movement, (3) passage of the bolus head through the fauces, (4) passage of the bolus tail through the fauces, and (5) onset and offset of upper esophageal sphincter (UES) opening. Calculated from these timings were the oral transit (tongue tip at incisors to passage of the bolus tail through the fauces), pharyngeal transit (bolus tail at fauces to offset of UES opening), pharyngeal clearance (bolus head at fauces to offset of UES opening), UES opening duration (time between onset and offset of UES opening), duration of hyoid movement (time between onset and end of the hyoid movement), oropharyngeal transit (tongue tip at incisors to offset of UES opening) and the relation of pharyngeal clearance duration/hyoid movement duration.

Statistical analysis was done by the Wilcoxon test. The differences were considered significant when $P<0.05$ in a two-tailed statistical analysis. The results are reported as median, the minimum and maximum (range) of values found, mean and standard deviation (SD), in milliseconds (msec). 


\section{Results}

The results for the bolus volumes of $5 \mathrm{~mL}$ and $10 \mathrm{~mL}$ are shown in Table 1, and for bolus consistency of thick liquid and honey thick are shown in Table 2.
A $10 \mathrm{~mL}$ bolus volume caused a longer UES opening duration than a $5 \mathrm{~mL}$ bolus volume (Fig. 1), for thick liquid bolus (5 mL: median 218 [range 120-510] milliseconds, $10 \mathrm{~mL}: 240$ [150-345] milliseconds, $P=0.010)$, and honey thick bolus (5 mL: 200 [110-375] milliseconds, 10 mL: 235 [130-535] milliseconds, $P=0.010]$. With thick liquid bolus the hyoid move-

Table 1. Oral and Pharyngeal Transit Duration, in Milliseconds, After Swallows of the Volumes of $5 \mathrm{~mL}$ and $10 \mathrm{~mL}$ Thick Liquid and Honey Thick Boluses

\begin{tabular}{|c|c|c|c|c|c|c|c|}
\hline & \multicolumn{3}{|c|}{$5 \mathrm{~mL}$} & \multicolumn{3}{|c|}{$10 \mathrm{~mL}$} & \multirow{2}{*}{$P$-value } \\
\hline & Mean (SD) & Median & Range & Mean (SD) & Median & Range & \\
\hline \multicolumn{8}{|c|}{ Thick Liquid } \\
\hline OT & $468(253)$ & 375 & $150-1190$ & 354 (128) & 335 & $165-655$ & 0.090 \\
\hline PT & $213(58)$ & 208 & $95-230$ & $223(108)$ & 203 & $75-690$ & 0.770 \\
\hline $\mathrm{PC}$ & 397 (133) & 375 & $195-775$ & $366(80)$ & 368 & $210-570$ & 0.490 \\
\hline UESO & $224(81)$ & 218 & $120-510$ & $242(46)$ & 240 & $150-345$ & 0.010 \\
\hline HM & $533(184)$ & 475 & $335-1225$ & $477(157)$ & 423 & $305-1085$ & 0.040 \\
\hline OPT & $729(316)$ & 635 & $380-1715$ & $594(203)$ & 515 & $290-1025$ & 0.070 \\
\hline \multicolumn{8}{|c|}{ Honey Thick } \\
\hline OT & $468(351)$ & 335 & $125-1525$ & $358(150)$ & 310 & $175-840$ & 0.430 \\
\hline PT & $229(71)$ & 225 & $60-405$ & $236(78)$ & 225 & $120-535$ & 0.850 \\
\hline $\mathrm{PC}$ & $474(263)$ & 390 & $190-1220$ & $480(277)$ & 410 & $212-1680$ & 0.210 \\
\hline UESO & $205(53)$ & 200 & $110-375$ & $248(96)$ & 235 & $130-535$ & 0.010 \\
\hline HM & $524(160)$ & 458 & $325-1100$ & $558(242)$ & 475 & $295-1280$ & 0.800 \\
\hline OPT & $757(470)$ & 568 & $280-2145$ & $696(296)$ & 623 & $344-1755$ & 0.600 \\
\hline
\end{tabular}

SD, standard deviation; OT, oral transit; PT, pharyngeal transit; PC, pharyngeal clearance; UESO, upper esophageal sphincter opening; HM, hyoid movement; OPT, oropharyngeal transit.

Table 2. Oral and Pharyngeal Transit Duration, in Milliseconds, After Swallows of Thick Liquid and Honey Thick Bolus Consistencies With the Volumes of $5 \mathrm{~mL}$ and $10 \mathrm{~mL}$

\begin{tabular}{|c|c|c|c|c|c|c|c|}
\hline & \multicolumn{3}{|c|}{ Thick liquid } & \multicolumn{3}{|c|}{ Honey thick } & \multirow{2}{*}{$P$-value } \\
\hline & Mean (SD) & Median & Range & Mean (SD) & Median & Range & \\
\hline \multicolumn{8}{|l|}{$5 \mathrm{~mL}$} \\
\hline OT & $468(253)$ & 375 & $150-1190$ & $468(351)$ & 335 & $125-1525$ & 0.510 \\
\hline PT & $213(58)$ & 208 & $95-230$ & $229(71)$ & 225 & $60-405$ & 0.030 \\
\hline $\mathrm{PC}$ & $397(133)$ & 375 & $195-775$ & $474(263)$ & 390 & $190-1220$ & 0.210 \\
\hline UESO & $224(81)$ & 218 & $120-510$ & 205 (53) & 200 & $110-375$ & 0.500 \\
\hline HM & $533(184)$ & 475 & $335-1225$ & $524(160)$ & 458 & $325-1100$ & 0.700 \\
\hline OPT & $729(316)$ & 635 & $380-1715$ & $757(470)$ & 568 & $280-2145$ & 0.850 \\
\hline \multicolumn{8}{|l|}{$10 \mathrm{~mL}$} \\
\hline OT & 354 (128) & 335 & $165-655$ & $358(150)$ & 310 & $175-840$ & 0.910 \\
\hline PT & $223(108)$ & 203 & $75-690$ & $236(78)$ & 225 & $120-535$ & 0.040 \\
\hline $\mathrm{PC}$ & $366(80)$ & 368 & $210-570$ & $480(277)$ & 410 & $212-1680$ & 0.010 \\
\hline UESO & $242(46)$ & 240 & $150-345$ & 248 (96) & 235 & $130-535$ & 0.450 \\
\hline HM & 477 (157) & 423 & $305-1085$ & $558(243)$ & 475 & $295-1280$ & 0.150 \\
\hline OPT & 594 (203) & 515 & $290-1025$ & $696(296)$ & 623 & $344-1755$ & 0.100 \\
\hline
\end{tabular}

SD, standard deviation; OT, oral transit; PT, pharyngeal transit; PC, pharyngeal clearance; UESO, upper esophageal sphincter opening; HM, hyoid movement; OPT, oropharyngeal transit. 
ment duration was longer for $5 \mathrm{~mL}$ (475 [335-1225] milliseconds) than for $10 \mathrm{~mL}$ (423 [305-108] milliseconds, $P=$ 0.040 , Table 1).

The pharyngeal transit was longer for honey thick bolus than for thick liquid (Fig. 2), with both the volume of $5 \mathrm{~mL}$ (thick liquid: 208 [95-230] milliseconds and honey thick: 225 [60-405] milliseconds and, $P=0.030$ ) and $10 \mathrm{~mL}$ (thick liquid: 203 [75-690] milliseconds and honey thick: 225 [120-535] milliseconds, $P=0.040)$. For pharyngeal clearance the difference was significant only with the $10 \mathrm{~mL}$ bolus volume (thick liquid: 368 [210-570] milliseconds and honey thick: 410 [212-1680] milliseconds, $P=0.010)$.

There was no difference associated with bolus volume or consistency in the relation between pharyngeal clearance duration and hyoid movement duration (Table 3 ).

\section{Discussion}

The results showed that the major influence of the increase in bolus volume from $5 \mathrm{~mL}$ to $10 \mathrm{~mL}$ was in the increase of upper

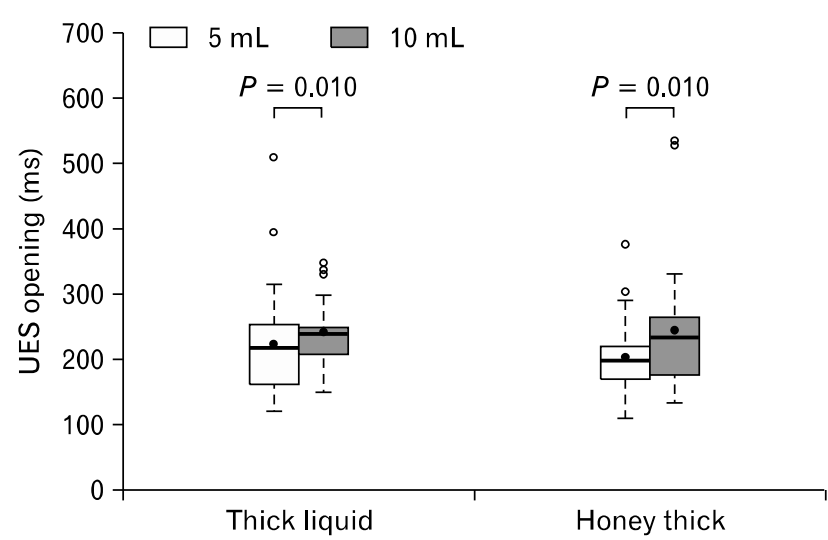

Figure 1. Upper Esophageal Sphincter (UES) opening duration after swallows of $5 \mathrm{~mL}$ and $10 \mathrm{~mL}$ of thick liquid and honey thick boluses in healthy subjects. esophageal sphincter opening duration, and of the increase of bolus consistency from thick liquid to honey thick was in the increase of pharyngeal transit duration. Both, bolus volume and consistency, do not change the proportion between the pharyngeal clearance duration/hyoid movement duration.

The viscosity of the bolus swallowed in this investigation was described in a previous publication to range from 4760 centipoise (cp) to $7115 \mathrm{cp}$ in thick liquid, and from $7630 \mathrm{cp}$ to $11850 \mathrm{cp}$ in honey thick. ${ }^{4}$ These boluses had narrow viscosity differences than the bolus utilized in another publication, when viscosity was 200 cp for liquid barium and $60000 \mathrm{cp}$ for paste barium. ${ }^{1}$ The influence in oral and pharyngeal transit was different. It was described that increase in bolus volume is related to an increase in UES opening duration, ${ }^{8,9}$ and that UES opening duration is longer with high-viscosity paste barium. ${ }^{1,8}$ The honey thick bolus we tested did not have a high consistency as the previous one. Bolus volume does not have influence on pharyngeal clearance duration, but a high viscous paste bolus has a longer pharyngeal clearance than a liquid bolus. ${ }^{1}$ These were the same results we found

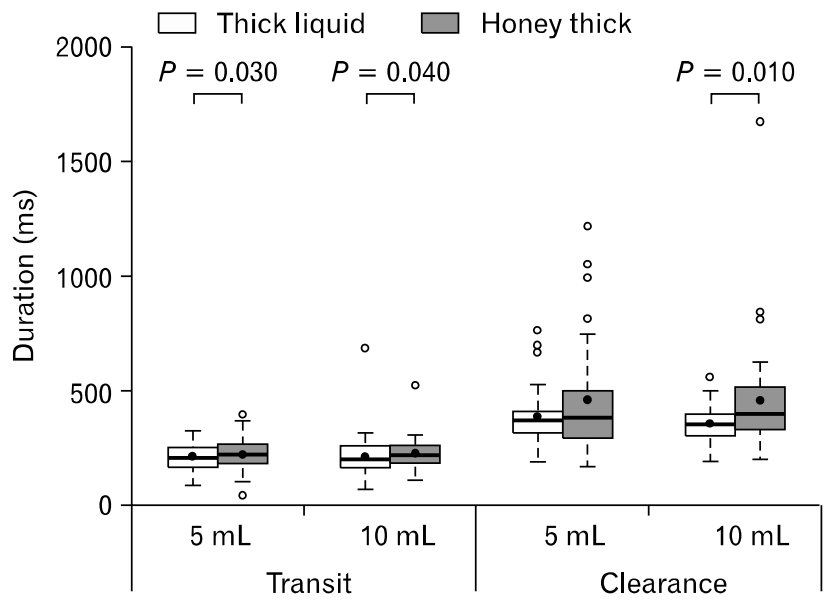

Figure 2. Pharyngeal transit duration and pharyngeal clearance duration after swallows of $5 \mathrm{~mL}$ and $10 \mathrm{~mL}$ of thick liquid and honey thick boluses in healthy subjects.

Table 3. Relation Between Pharyngeal Clearance Duration and Hyoid Movement Duration After Swallows of $5 \mathrm{~mL}$ and $10 \mathrm{~mL}$ of Thick Liquid and Honey Thick Boluses

\begin{tabular}{|c|c|c|c|c|c|c|c|}
\hline & \multicolumn{3}{|c|}{ Thick liquid } & \multicolumn{3}{|c|}{ Honey thick } & \multirow{2}{*}{$P$-value } \\
\hline & Mean (SD) & Median & Range & Mean (SD) & Median & Range & \\
\hline $5 \mathrm{~mL}$ & $0.82(0.35)$ & 0.77 & $0.21-1.70$ & $0.97(0.58)$ & 0.77 & $0.27-2.41$ & 0.470 \\
\hline $10 \mathrm{~mL}$ & $0.84(0.32)$ & 0.80 & $0.19-1.69$ & $0.92(0.43)$ & 0.77 & $0.31-2.24$ & 0.520 \\
\hline$P$-value & 0.440 & & & 0.640 & & & \\
\hline
\end{tabular}

$\mathrm{SD}$, standard deviation. 
with a thick liquid and honey thick consistencies.

Swallowing a high-density liquid barium preparation causes a slower pharyngeal transit time and a longer UES opening duration than a low-density liquid barium preparation, showing that the density as well as viscosity has an influence on bolus transit time through the pharynx. ${ }^{10,11}$

Although there are differences in the UES transit with different bolus volumes and differences in pharyngeal transit with different bolus consistencies, the proportion between pharyngeal clearance and hyoid movement is the same. It is a demonstration of the precise control of the swallowing events, both in liquid and high viscous bolus.

Previous publications have already demonstrated that an increase in bolus volume causes an increase in UES opening duration and UES transit, ${ }^{1,7-10,12,13}$ however, each investigation evaluated different bolus preparation. In this investigation, with the thick liquid and honey thick consistency, the effect of bolus volume was demonstrated and was the same at different bolus consistencies. The longer UES transit should be consequence of the increase of bolus length with the increase in bolus volume, in mouth and pharynx, with liquid and paste bolus ${ }^{1}$ which causes an early bolus arrival at the UES, early UES opening and longer UES flow. ${ }^{12}$

The longer pharyngeal transit with paste bolus compared with liquid bolus was seen in a previous publication with a bolus volume from $2 \mathrm{~mL}$ to $20 \mathrm{~mL}$, without influence of bolus volume. ${ }^{1}$ However, this previous investigation used low-viscosity liquid barium and a viscous barium paste with high viscosity. ${ }^{1}$ With the smaller difference in consistency between thick liquid and honey thick bolus we used, increased viscosity was also demonstrated to be associated with a decrease in pharyngeal flow.

A possible explanation for longer UES transit with the increase of bolus volume and also for longer pharyngeal transit with increase in bolus viscosity is the modulation of the deglutitive inhibition in the skeletal muscle of the proximal esophagus, which is consequence of the inhibition of neuronal discharges in the brain stem. $^{14}$

The results indicated that in the treatment of patients with impairment of UES opening the bolus volume of each swallow should be small, which causes a longer time to eat a meal, and patients who is unable to create enough pharyngeal pressure, essential for pharyngeal transit, should not swallow a viscous bolus, which need a higher pharyngeal pressure, compared with swallow of a liquid bolus. ${ }^{1}$

In conclusion, an increase in the swallowed bolus volume causes a longer UES opening duration, and an increase in bolus consistency causes a longer pharyngeal transit duration, however, the proportion between pharyngeal clearance and hyoid movement duration does not change with bolus volume or bolus consistency.

\section{References}

1. Dantas R, Kern M, Massey B, et al. Effect of swallowed bolus variables on oral and pharyngeal phases of swallowing. Am J Physiol 1990;258(5 Pt 1):G675-G681.

2. Lang IM. Brain stem control of the phases of swallowing. Dysphagia 2009;24:333-348

3. Ryan C, Hummel T. Gustation, olfaction and deglutition. In: Shaker R, Belafsky P, Postma G, Easterling C, eds. Principles of deglutition. 1. New York: Springer 2013:19-24.

4. Costa MM, Almeida JT, Sant'Anna E, Pinheiro GM. Viscosities reproductive patterns for use in videofluoroscopy and rehabilitation therapy of dysphagic patients. Arq Gastroenterol 2007;44:297-303.

5. Molfender SM, Steele CM. Temporal variability in the deglutition literature. Dysphagia 2012;27:162-177.

6. Cichero JA, Steele C, Duivestein J, et al. The need for international terminology and definitions for texture-modified foods and thickened liquids used in dysphagia management: foundations of a global initiative. Curr Phys Med Rehabil Rep 2013;24:280-291.

7. Cook IJ, Dodds WJ, Dantas RO, et al. Opening mechanisms of the human upper esophageal sphincter. Am J Physiol 1989;257(5 Pt 1):G748-G759.

8. Lazarus CL, Logemann JA, Rademaker AW, et al. Effect of bolus volume, viscosity and repeated swallows in nonstroke subjects and stroke patients. Arch Phys Med Rehabil 1993;10:1066-1070.

9. Molfender SM, Steele CM. Variation in temporal measures of swallowing: sex and volume effects. Dysphagia 2013;28:226-233.

10. Dantas RO, Dodds WJ, Massey BT, Kern MK. The effect of highvs low-density barium preparation on the quantitative features of swallowing. AJR Am J Roentgenol 1989;15:1191-1195.

11. Stokely SL, Molfenter SM, Steele CM. Effects of barium concentration on oropharyngeal swallow timing measures. Dysphagia 2014; 29:78-82.

12. Cook IJ, Dodds WJ, Dantas RO, et al. Timing of videofluoroscopic, manometric events, and bolus transit during the oral and pharyngeal phases of swallowing. Dysphagia 1989;4:8-15.

13. Kendall KA, McKenzie S, Leonard RJ, Gonçalves MI, Walker A. Timing of events in normal swallowing: a videofluoroscopic study. Dysphagia 2000;15:74-83.

14. Sifrim D, Jafari J. Deglutitive inhibition, latency between swallow and esophageal contractions and primary esophageal motor disorders. J Neurogastroenterol Motil 2012;18:6-12. 